\title{
ETNOBOTANI BAMBU OLEH MASYARAKAT DI SEKITAR HUTAN DESA LANDAU GARONG KABUPATEN MELAWI
}

\author{
(Ethnobotany Bamboo By Community Around The Forest Village Of Landau Garong \\ Melawi District)
}

\author{
Wiwin Retnawati, Evy Wardenaar, Siti Masitoh Kartikawati \\ Fakultas Kehutanan Universitas Tanjungpura. Jalan Imam Bonjol Pontianak 78124 \\ Email: wiwinnurhatta@gmail.com
}

\begin{abstract}
The people of Landau Garong village have a direct relationship with plants in their traditional use (ethnobotany), especially bamboo. Bamboo in the village is very abundant so that many people use it in various needs according to their skills. The purpose of this study was to record and document the types used and find out patterns of utilization of bamboo by the community around the village forest Landau Garong Melawi district. The benefit of this research is to inform the community outside the Landau Garong village about the types of bamboo and their sustainable use patterns by the community around the Landau Garong village forest. This study uses a survey method with data collection techniques using the PRA method. Data obtained through observation and interviews. Data collected in the form of primary data and secondary data. Based on the results in the field, I obtained 6 types of bamboo, namely Gigantochloa hasskarliana, Bambusa vulgaris var.vulgaris, Schizostachyum brachycladum, Schizostachyum flexuosum, Gigantochloa balui dan Gigantochloa levis. There are 6 types of use of bamboo by the community, namely as building materials, craft materials (household crafts and fish trap crafts), food ingredients, traditional ritual materials, agricultural equipment materials, and traditional game materials.
\end{abstract}

Keywords: Ethnobotany, Bamboo, Community Around The Forest, Landau Garong Village

\section{PENDAHULUAN}

Bambu merupakan salah satu hasil hutan bukan kayu yang banyak ditemukan di daerah tropik yaitu Benua Asia, Afrika, Amerika dan Australia. Bambu juga tersebar di daerah subtropik dan daerah beriklim sedang. Bambu di Indonesia dapat dijumpai di daerah pedesaan maupun di dalam kawasan hutan. Diperkirakan terdapat 1.642 jenis bambu (Vorontsova et al. 2016), di mana 176 jenis terdapat di Indonesia dan 105 jenis di antaranya merupakan endemik Indonesia (Widjaja. 2019).
Bambu di Indonesia memegang peranan sangat penting bagi masyarakat, karena relatif murah dan mudah didapat. Pemanfaatan tumbuhan bambu secara tradisional (etnobotani) oleh masyarakat di tiap daerah sangat beragam. Menurut Munziri et.al (2013) bambu dimanfaatkan masyarakat Desa Saham Kecamatan Sengah Temila Kabupaten Landak sebagai makanan, konstruksi, kerajinan, alat musik, upacara adat, dan tanaman hias.

Desa Landau Garong merupakan salah satu desa yang ada di Kecamatan Pinoh Selatan Kabupaten Melawi. Desa 
ini terdiri dari 2 dusun yaitu Dusun Landau Garong dan Dusun Jambu dengan luas wilayah $56.000 \mathrm{Ha}$. Masyarakat Desa Landau Garong merupakan etnis Dayak Kebahan, yang memiliki pengetahuan tentang pemanfaatan tumbuhan, khususnya bambu. Masyarakat memanfaatkan bambu untuk memenuhi kebutuhan sehari-hari mereka tidak untuk diperjualbelikan. Secara tradisional masyarakat Desa Landau Garong memanfaatkan bambu sebagai bahan material bangunan, bahan kerajinan, bahan pangan, bahan ritual adat, bahan pertanian, dan bahan alat permainan tradisional. Namun hingga saat ini belum diperoleh data dan dokumentasi jenis - jenis dan pola pemanfaatan bambu yang digunakan oleh masyarakat Desa Landau Garong tersebut. Agar pengetahuan secara tradisional tersebut tidak hilang, maka dilakukan penelitian untuk mengetahui pola pemanfaatan bambu yang dimanfaatkan masyarakat Desa Landau Garong Kecamatan Pinoh Selatan Kabupaten Melawi.

Tujuan dari penelitian ini adalah untuk mendata dan mendokumentasikan jenis - jenis bambu yang dimanfaatkan dan mengetahui pola pemanfaatan bambu oleh masyarakat di sekitar hutan Desa Landau Garong Kecamatan Pinoh Selatan Kabupaten Melawi. Manfaat penelitian adalah untuk menginformasikan kepada masyarakat di luar Desa Landau Garong tentang jenis - jenis bambu yang dimanfaatkan dan pola pemanfaatannya secara lestari oleh masyarakat di sekitar hutan Desa Landau Garong Kabupaten Melawi.

\section{METODE PENELITIAN}

Penelitian ini dilaksanakan di Desa Landau Garong, yang terdiri dari Dusun Landau Garong dan Dusun Jambu, Kecamatan Pinoh Selatan, Kabupaten Melawi selama kurang lebih 1 bulan di lapangan, dimulai dari tanggal 07 Juni 2019 sampai 07 Juli 2019.

Alat yang digunakan dalam penelitian adalah kamera, rekaman, parang, logbook, buku identifikasi bambu (Widjaja, 2001). Objek yang digunakan dalam penelitian ini adalah bambu dan masyarakat Desa Landau Garong Kecamatan Pinoh Selatan Kabupaten Melawi.

Metode yang digunakan dalam penelitian ini adalah metode survey dengan teknik pengumpulan data menggunakan metode PRA (Participatory Rural Appraisal) Sudjana (2001). Data diperoleh melalui observasi dan wawancara yang dibantu dengan tallysheet. Data yang dikumpulkan berupa data primer dan data sekunder. Data primer terdiri dari jenis-jenis bambu yang dimanfaatkan dan pola manfaat bambu meliputi, penggunaan bambu, jenis bambu yang digunakan, bagian bambu yang digunakan, dan cara pengolahan. Sedangkan untuk data sekunder meliputi keadaan umum dan lokasi, kondisi sosial budaya masyarakat. Analisis data dalam penelitian ini menggunakan metode deskriptif kualitatif.

\section{HASIL DAN PEMBAHASAN}

Desa Landau Garong merupakan salah satu desa yang ada di Kecamatan Pinoh Selatan Kabupaten Melawi, di 
mana masyarakat desa tersebut bersuku Dayak Kebahan, yang memanfaatkan hasil hutan bukan kayu khususnya bambu untuk memenuhi kebutuhan sehari-hari mereka. Berdasarkan hasil identifikasi dan wawancara dengan masyarakat Desa Landau Garong untuk memenuhi kebutuhan sehari - hari mereka memanfaatkan sebanyak 6 jenis bambu dan sebanyak 19 jenis manfaat bambu yang dihasilkan. Hal ini menunjukkan bahwa dalam
Garong memiliki hubungan dengan tumbuhan bambu untuk menunjang kelangsungan hidup mereka.

Jenis - jenis Bambu yang dimanfaatkan

Berdasarkan hasil identifikasi dan wawancara terhadap masyarakat yang mengetahui jenis bambu, maka diperoleh 6 jenis bambu yang tergolong ke dalam 3 genus yaitu Gigantochloa, Bambusa dan Schizostachyum. Secara lebih lengkap dapat dilihat pada Tabel 1.

kesehariannya, masyarakat Desa Landau

Tabel 1. Jenis-jenis ambu yang dimanfaatkan oleh masyarakat Desa Landau Garong (Types Of Bamboo Used By The Landau Garong Villagers).

\begin{tabular}{lllll}
\hline No. & Nama Lokal & $\begin{array}{l}\text { Nama } \\
\text { Indonesia }\end{array}$ & Nama Ilmiah & Habitat \\
\hline 1 & Lingkau & Lengka Tali & Gigantochloa hasskarliana & $\begin{array}{l}\text { Tepi sungai dan } \\
\text { Dataran rendah } \\
\text { Tepi sungai dan }\end{array}$ \\
2 & Ao & Aor & Bambusa vulgaris var.vulgaris & $\begin{array}{l}\text { Dataran rendah } \\
\text { Dataran rendah }\end{array}$ \\
3 & Buluh & Lemang & Schizostachyum brachycladum & $\begin{array}{l}\text { Dataran rendah } \\
\text { Tepi sungai }\end{array}$ \\
5 & Kinyel & Kauayan & Schizostachyum flexuosum & Gigantochloa balui \\
6 & Porin Anyang & Balui & Tepi Sungai \\
\hline
\end{tabular}

Berdasarkan observasi dan informasi dari masyarakat Desa Landau Garong, dari ke-6 jenis bambu tersebut yang paling sedikit tumbuh adalah bambu porin manis. Menurut hasil penelitian Usman (2019) di Desa Babane Kecamatan Samalantan Kabupaten Bengkayang ditemukan 8 jenis bambu, yaitu tarenk kuning (Bambusa vulgaris), betung (Dendrocalamus asper), aur (Bambusa multiplex), buluh (Schizostachyum zollinggeri), munti (Gigantochloa sp), pasak
(Schizostachyum lima), tarenk (Gigantochloa atter), bangking (Gigantochloa balui).

Bentuk Pemanfaatan yang dihasilkan

Masyarakat Desa Landau Garong memanfaatkan bambu dalam berbagai penggunaan yaitu sebagai bahan material bangunan, bahan kerajinan (kerajinan rumah tangga dan kerajinan perangkap ikan), bahan pangan, bahan ritual adat, bahan peralatan pertanian dan bahan alat permainan tradisional. Untuk lebih jelas dapat dilihat pada Tabel 2. 
Tabel 2. Pemanfaatan Bambu Oleh Masyarakat Desa Landau Garong (The Use Of Bamboo By Landau Garong Villagers).

\begin{tabular}{|c|c|c|c|}
\hline No & Jenis Manfaat & Bentuk Pemanfaatan & Jenis Bambu \\
\hline 1 & Material Bangunan & $\begin{array}{l}\text { Kandang Ternak, Kerangka } \\
\text { Tenda }\end{array}$ & $\begin{array}{l}\text { Ao, Porin Anyang, } \\
\text { Lingkau }\end{array}$ \\
\hline 2 & $\begin{array}{l}\text { Kerajinan (Rumah Tangga } \\
\text { dan Perangkap Ikan) }\end{array}$ & $\begin{array}{l}\text { Capan, Ronjong, } \begin{array}{r}\text { Ragak, } \\
\text { Timpak, }\end{array} \\
\text { Semakak, } \\
\text { Asbak, Bubu, Pemansai. }\end{array}$ & Buluh, Kinyel, Ao \\
\hline 3 & Pangan & Sayuran dan Lalapan, Bokat & $\begin{array}{l}\text { Lingkau, Porin } \\
\text { Manis, Kinyel, Buluh }\end{array}$ \\
\hline 4 & Ritual Adat & $\begin{array}{l}\text { Kelongkang Sasak, } \\
\text { Kelongkang Bukuk }\end{array}$ & Buluh, Lingkau \\
\hline 5 & Peralatan Pertanian & Tempurong Karet & Ao \\
\hline 6 & Alat Permainan Tradisional & Senapang Lepok & Porin Manis \\
\hline
\end{tabular}

Tabel 2 menunjukkan bahwa dari ke-6 jenis bambu tersebut yang paling banyak dimanfaatkan masyarakat Desa Landau Garong adalah jenis bambu buluh dan bambu kinyel, karena jenis bambu ini mudah untuk dibentuk, diolah, dan berdinding tipis. Masyarakat Desa Landau Garong banyak memanfaatkan bambu buluh dan bambu kinyel sebagai bahan peralatan rumah tangga atau bahan kerajinan anyaman, karena ibuibu di desa tersebut memanfaatkan waktu luang dengan menganyam. Dari ke 6 jenis bambu tersebut dapat

Tabel 3. Jenis Bambu dan Bentuk Pemanfaatan (Bamboo Types And Forms Of

\begin{tabular}{llll}
\hline No. & Jenis Bambu & Bentuk Pemanfaatan & Jumlah \\
\hline 1 & Lingkau & $\begin{array}{l}\text { Kandang Ternak, Kerangka Tenda, Sayuran dan Lalapan, } \\
\text { Kelongkang Sasak, Kelongkang Bukuk. }\end{array}$ \\
2 & Ao & $\begin{array}{l}\text { Kandang Ternak, Kerangka Tenda, Asbak, Tempurong } \\
\text { Karet. }\end{array}$ \\
& $\begin{array}{l}\text { Capan, Ronjong, Ragak, Timpak, Lengkak, Semanggang, } 12 \\
\text { Bakol, Rojut, Bubu, Pemansai, Kelongkang Sasak, }\end{array}$ \\
& Buluh & $\begin{array}{l}\text { Kelongkang Bukuk. } \\
\text { Capan, Ronjong, Ragak, Timpak, Lengkak, Semanggang, }\end{array}$ \\
4 & Kinyel & $\begin{array}{l}\text { Bakol, Rojut, Pemansai, Sayuran dan Lalapan. } \\
\text { Kandang Ternak, Kerangka Tenda. }\end{array}$ & 2 \\
5 & Porin Anyang & $\begin{array}{l}\text { Sayuran dan Lalapan, Senapang Lepok. } \\
6\end{array}$ & Porin Manis
\end{tabular}

digunakan untuk membuat berbagai bentuk pemanfaatan, di mana satu jenis bambu dapat membuat 2 atau lebih bentuk pemanfaatan yang disajikan dalam Tabel 3. Menurut hasil penelitian Rahmawati et.al (2019) masyarakat di Desa Leu Kabupaten Bima hanya menggunakan bambu tali (Gigantochloa hasskarliana) dikarenakan bambu ini banyak tumbuh di desa tersebut dan hanya memanfaatkannya sebagai bahan bangunan dan bahan industri rumah tangga dan kerajinan tangan.

\section{Utilization).}




\section{Bambu Sebagai Bahan Material Bangunan}

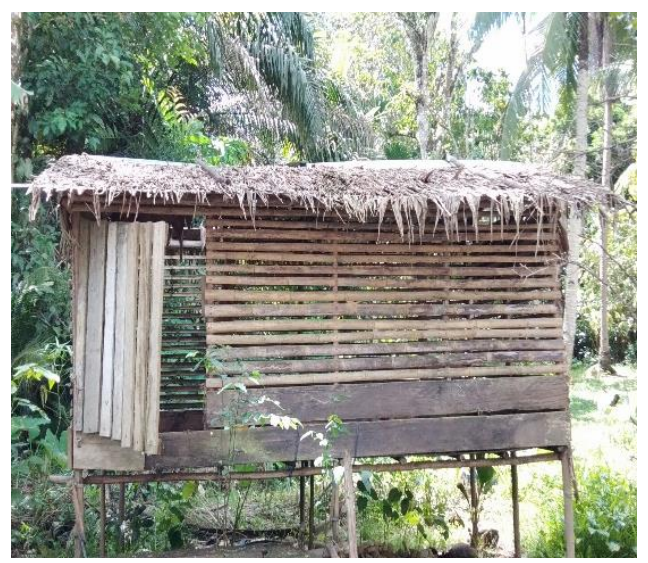

(a)
Bambu dimanfaatkan masyarakat sebagai bahan bangunan seperti kandang ternak dan kerangka tenda.

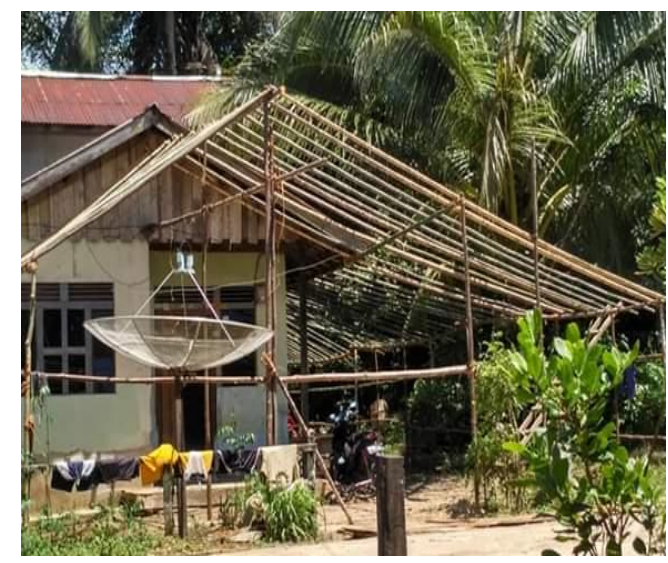

(b)

Gambar 1. Bambu untuk Material Bangunan (a) Kandang Ternak (b) Kerangka Tenda (Bamboo for building materials (a) Kandang Ternak (b) Kerangka Tenda)

\section{a. Kandang Ternak}

Kandang ternak berfungsi untuk mengurung ayam, dan bebek. Pemanfaatan bambu sebagai kandang ternak sangat banyak ditemukan di Desa Landau Garong.

\section{b. Kerangka Tenda}

Tidak hanya sebagai bahan kandang ternak, masyarakat di Desa Landau Garong juga memanfaatkan bambu sebagai kerangka tenda. Kerangka tenda biasanya digunakan masyarakat untuk kegiatan atau acara pernikahan, acara pengajian (majelis taklim), dan acara khitanan.

\section{Bambu sebagai Bahan Kerajinan}

Masyarakat Desa Landau Garong juga memanfaatkan bambu sebagai bahan kerajinan berupa kerajinan rumah tangga yang meliputi Capan, Ronjong, Ragak, Timpak, Lengkak, Semanggang, Bakol, Rojut dan Asbak, dan kerajinan perangkap ikan yang meliputi Bubu, dan Pemansai. Motif anyaman di Desa Landau Garong menggunakan motif tunggal (meniri) dan motif bersilang ganda (menua). Produk kerajinan tersebut tidak diberi warna. Masyarakat tersebut hanya memanfaatkan hasil kerajinan untuk keperluan sehari-hari mereka tidak untuk diperjual belikan. Menurut hasil penelitian Murti dan Murwandani (2018) masyarakat Sanggar Hamid Jaya Desa Gintangan Kecamatan Rogojampi Kabupaten Banyuwangi menggunakan 4 motif anyaman untuk kerajinan yaitu motif truntum, motif pipil, motif liris dan motif moto puru. Warna yang digunakan adalah pewarna sintetis yaitu sumbo (wenter).

\section{Bambu sebagai Bahan Kerajinan Rumah Tangga}

a. Capan

Capan berfungsi untuk menampi padi atau beras. Capan berbentuk segi empat. Menurut penelitian Usman (2019) penampi beras di Desa Babane 
Kecamatan Samalantan Kabupaten Bengkayang disebut Nyiro (berbentuk lingkaran). Cara menggunakan capan yaitu dipegang kedua sisinya agar beras tidak tumpah. Capan dianyam dengan motif tunggal (meniri). Capan terbuat dari bambu buluh (Schizostachyum brachycladum) dan bambu kinyel (Schizostachyum flexuosum).

\section{b. Ronjong}

Ronjong yaitu berfungsi untuk menyimpan tangkapan ikan pada saat mansai dan mancing, menyimpan pisok untuk menoreh batang karet. Ronjong berbentuk bulat memanjang dan pada bagian atasnya diberi bingkai. Cara menggunakan ronjong adalah kaitkan tali dibahu. Biasanya ronjong terbuat dari bambu kinyel (Schizostachyum flexuosum) dan bambu buluh (Schizostachyum brachycladum). Ronjong dianyam dengan motif tunggal (meniri).

\section{c. Ragak}

Ragak berfungsi untuk menyimpan sayur sebelum dan sesudah dicuci. Pada bagian atas ragak berbentuk bulat, agak melebar dan diberi bingkai sedangkan pada bagian bawah berbentuk segi empat. Cara menggunakan ragak yaitu pegang bagian sisinya. Ragak terbuat dari bambu kinyel (Schizostachyum flexuosum) dan bambu buluh (Schizostachyum brachycladum). Ragak dianyam dengan 2 motif yaitu bagian bawah menggunakan motif tunggal (meniri) dan bagian atas menggunakan motif bersilang ganda (тепиа).

\section{d. Timpak}

Timpak berfungsi untuk menyimpan bekal atau barang - barang yang akan dibawa ke ladang dan kebun, dan juga bisa digunakan untuk mencuci beras pulut untuk membuat lemang. Timpak berbentuk bulat pada bagian atas dan diberi bingkai sedangkan pada bagian bawah berbentuk segi empat. Cara menggunakan timpak yaitu kaitkan tali dibahu atau dikepala. Bambu yang digunakan untuk membuat timpak adalah bambu kinyel (Schizostachyum flexuosum) dan bambu buluh (Schizostachyum brachycladum). Timpak dianyam dengan motif tunggal (meniri).

\section{e. Lengkak}

Lengkak berfungsi untuk menyimpan bekal atau barang ke ladang dan kebun, lengkak juga digunakan untuk menyimpan padi setelah dipanen dan menyimpan beras setelah ditumbuk. Lengkak terbuat dari bambu kinyel (Schizostachyum flexuosum) dan bambu buluh (Schizostachyum brachycladum). Lengkak dianyam menggunakan 2 motif yaitu bagian bawah dianyam menggunakan motif bersilang ganda (menua) dan bagian atas menggunakan motif tunggal (meniri). Lengkak berbentuk bulat pada bagian atasnya, dibagian bawahnya berbentuk segi empat dan diberi bingkai pada kedua bagian tersebut. Cara menggunakan lengkak sama dengan timpak yaitu kaitkan tali dibahu dan dikepala. 


\section{f. Semanggang}

Semanggang berfungsi untuk menyimpan bawang dan bumbu dapur, semanggang juga digunakan untuk menyimpan sayur seperti ragak. Semanggang terbuat dari bambu kinyel (Schizostachyum flexuosum) dan bambu buluh (Schizostachyum brachycladum). Semanggang berbentuk bulat panjang dan dianyam tidak rapat pada bagian bawah dan sampingnya. Bentuk semanggang hampir sama dengan ragak, ragak panjang ke atas sedangkan semanggang panjang ke samping, namun keduanya sama dibingkai pada bagian atasnya. Cara menggunakan semanggang juga hampir sama dengan pemansai yaitu pegang kedua sisinya. Semanggang dianyam dengan 2 motif yaitu bagian bawah menggunakan motif tunggal (meniri) dan bagian atas menggunakan motif bersilang ganda (menua).

\section{g. Bakol}

Bakol berfungsi untuk mencuci beras. Bakol berbentuk bulat, ujung atasnya agak lebar sedangkan pada bagian bawahnya berbentuk segi empat. Bakol biasanya dibuat dengan menggunakan bambu buluh
(Schizostachyum brachycladum) dan bambu kinyel (Schizostachyum flexuosum). Cara menggunakan bakol yaitu pegang sisi kiri dan sisi kanannya. Bakol dianyam dengan menggunakan motif tunggal (meniri).

\section{h. Rojut}

Rojut berfungsi untuk menyimpan beras yang sudah ditumbuk dan menyimpan padi pada saat pemanenan. Rojut berbentuk bulat memanjang, pada bagian atas diberi bingkai dan bagian bawah berbentuk segi empat, bentuk rojut hampir sama dengan timpak. Cara menggunakan rojut sama dengan timpak, lengkak, ronjong yaitu kaitkan tali dibahu dan dikepala. Bambu yang digunakan untuk membuat rojut adalah bambu kinyel (Schizostachyum flexuosum) dan buluh (Schizostachyum brachycladum). Rojut dianyam dengan menggunakan motif tunggal (meniri).

\section{i. Asbak}

Asbak yaitu berfungsi untuk menyimpan putung rokok. Bambu yang digunakan untuk membuat asbak pada umumnya adalah jenis bambu ao (Bambusa vulgaris var.vulgaris). Asbak berbentuk bulat panjang. 


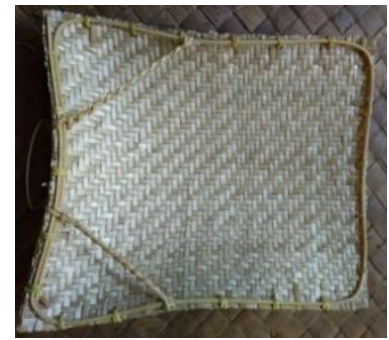

(a)

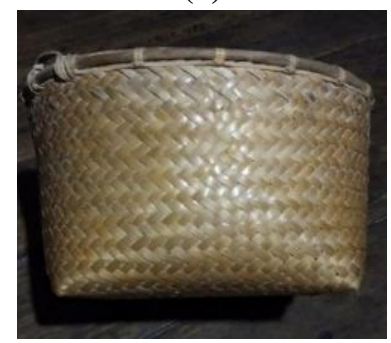

(d)

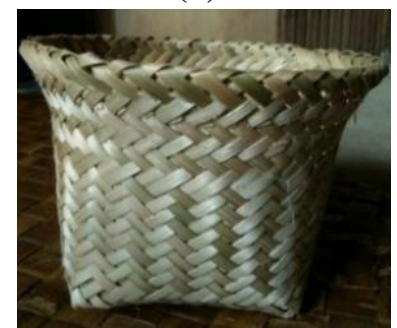

(g)

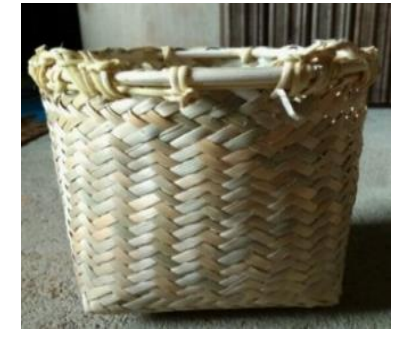

(b)

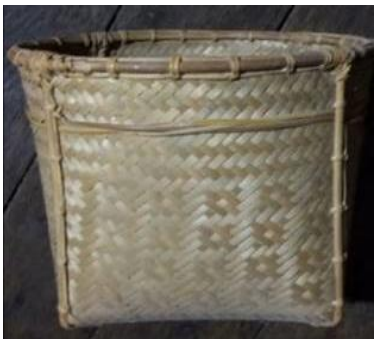

(e)

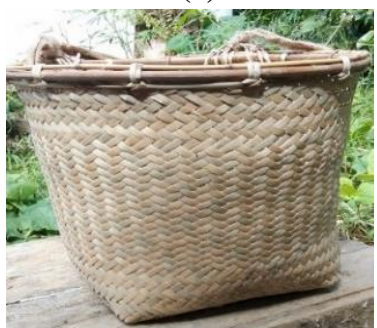

(h)

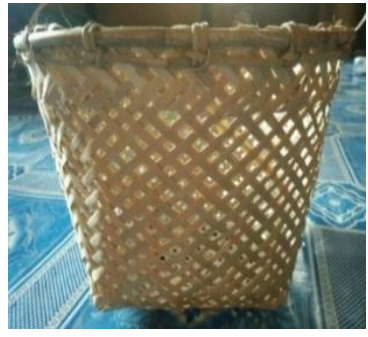

(c)

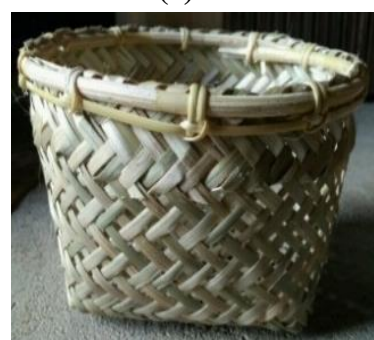

(f)

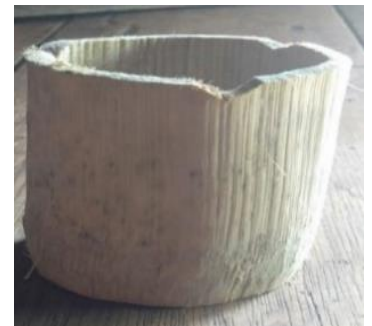

(i)

Gambar 2. Bambu untuk Kerajinan Rumah Tangga (a) Capan (b) Ronjong (c) Ragak (d) Timpak (e) Lengkak (f) Semanggang (g) Bakol (h) Rojut (i) Asbak (Bamboo for Household Crafts (a) Capan (b) Ronjong (c) Ragak (d) Timpak (e) Lengkak (f) Semanggang (g) Bakol (h) Rojut (i) Asbak)

\section{Bambu Sebagai Bahan Kerajinan Perangkap Ikan}

\section{a. Bubu}

Bubu berbentuk memanjang, di dalamnya memiliki penyaring yang berfungsi untuk pintu masuknya ikan dan perangkap ikan agar ikan tersebut tidak dapat keluar, penyaring tersebut masyarakat Desa Landau Garong biasa menyebutnya ijab. Bubu terbuat dari bambu buluh (Schizostachyum brachycladum). Bubu biasanya dipasang di parit pemantang sawah dan di sungai. Biasanya yang menganyam bubu adalah laki-laki, khususnya bapak-bapak. Bubu dianyam pada saat malam hari karena pada waktu tersebut mereka memiliki waktu luang untuk menganyam bubu, karena pada saat siang hari mereka bekerja sebagai petani (karet dan berladang). Bubu dibuat dengan jumlah bilah ganjil karena dipercaya jika bubu dibuat dengan jumlah bilah genap ikan tidak akan masuk. Menurut penelitian Usman (2019) perangkap ikan di Desa Babane Kecamatan Samalantan Kabupaten Bengkayang disebut Antiing (berbentuk kerucut) dan Bubu Ikan (berbentuk selinder). 


\section{b. Pemansai}

Pemansai digunakan masyarakat Desa Landau Garong khususnya ibu-ibu untuk menangkap ikan di sungai atau di pemantang parit sawah. Pemansai terbuat dari bambu kinyel (Schizostachyum flexuosum) dan bambu buluh (Schizostachyum brachycladum). Pemansai berbentuk memanjang. Cara menggunakan pemansai yaitu pegang

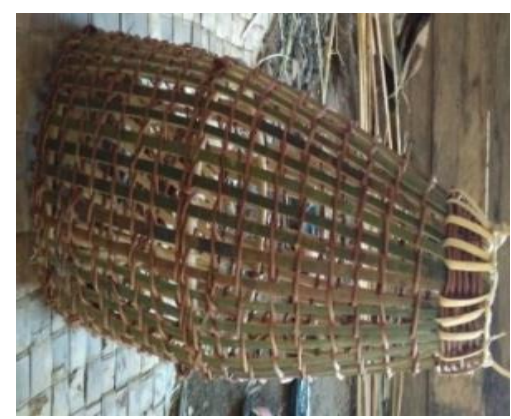

(a) kedua sisinya yaitu sisi kiri dan sisi kanan dan biasanya di bentang sesuai arah dan besarnya ukuran sungai dan parit sawah. Pemansai tidak boleh diletakkan di atas kepala, karena dipercaya masyarakat jika diletakkan di atas kepala akan mendapatkan ular. Pemansai dianyam dengan menggunakan motif tunggal (meniri).

Gambar 3. Bambu untuk Kerajinan Perangkap Ikan (a) Bubu (b) Pemansai (Bamboo to Craft Fish Traps (a) Bubu (b) Pemansai)

\section{Bambu sebagai Bahan Pangan}

Menurut hasil penelitian Arsad et.al (2015) rebung bambu dapat dimanfaatkan sebagai bahan pangan seperti kripik, sayuran dan tepung.

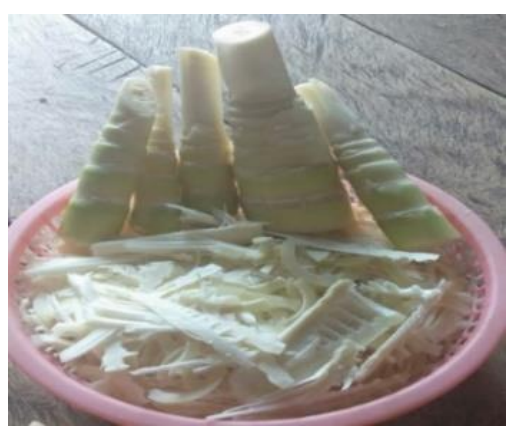

(a)
Namun di Desa Landau Garong rebung bambu dimanfaatkan masyarakat sebagai bahan pangan berupa sayuran dan lalapan dan bokat (lemang bambu).

Gambar 4. Bambu untuk Pangan (a) Sayuran dan Lalapan (b) Bokat (Lemang) (Bamboo for Food (a) Vegetables (b) Bamboo Lemang)

\section{a. Sayuran dan Lalapan}

Masyarakat Desa Landau Garong memanfaatkan tunas bambu sebagai sayuran dan lalapan. Tunas atau rebung bambu yang digunakan sebagai sayuran dan lalapan adalah bambu lingkau 
(Gigantochloa hasskarliana) bambu kinyel (Schizostachyum flexuosum) dan porin manis (Gigantochloa levis) dikarenakan bambu jenis ini tidak pahit. Tunas bambu biasanya digunakan masyarakat sebagai sayuran dan beculit (lalapan).

\section{b. Bokat}

Bambu buluh (Schizostachyum brachycladum) juga dimanfaatkan masyarakat Desa Landau Garong untuk membuat bokat (lemang bambu), karena bambu buluh berdiameter besar, berdinding tipis sehingga bokat cepat matang. Bokat berbentuk bulat panjang. Biasanya masyarakat membuat bokat pada saat bulan suci ramadhan dan acara melabo atau makan bersama.

\section{Bambu sebagai Bahan Ritual}

Bambu dimanfaatkan masyarakat Desa Landau Garong sebagai bahan ritual adat seperti ritual berladang dan pindah rumah baru. Ritual berladang dilakukan di uma (ladang), ritual tersebut bertujuan agar tanah menjadi subur dan hasil panen melimpah. Dan ritual pindah rumah baru dipercaya masyarakat untuk mengusir hantu agar tidak mengganggu.

\section{a. Kelongkang Sasak}

Kelongkang sasak biasanya digunakan masyarakat untuk ritual adat berladang, dan adat pindah rumah baru. Kelongkang sasak terbuat dari bambu buluh (Schizostachyum brachycladum) dan bambu lingkau (Gigantochloa hasskarliana), kelongkang sasak berbentuk segi empat. Cara menggunakan kelongkang sasak yaitu gantung kelongkang tersebut di penyangga. Isi yang akan dimasukkan di dalam kelongkang sasak berupa darah, kaki, kepala ayam, paku, serabi topong tabar, lempin, daun mali-mali dan beras kuning.

\section{b. Kelongkang Bukuk}

Kelongkang bukuk yaitu berfungsi sebagai ritual adat sama halnya dengan kelongkang sasak yaitu untuk adat berladang, dan adat rumah baru. Kelongkang bukuk terbuat dari bambu buluh (Schizostachyum brachycladum) dan lingkau (Gigantochloa hasskarliana), kelongkang bukuk berbentuk panjang dan melebar ke atas. Cara menggunakannya juga sama dengan kelongkang sasak yaitu gantung di penyangga. Isi yang akan dimasukkan di dalam kelongkang bukuk sama halnya dengan kelongkang sasak berupa darah, kaki, kepala ayam, paku, serabi topong tabar, lempin, daun mali-mali dan beras kuning 


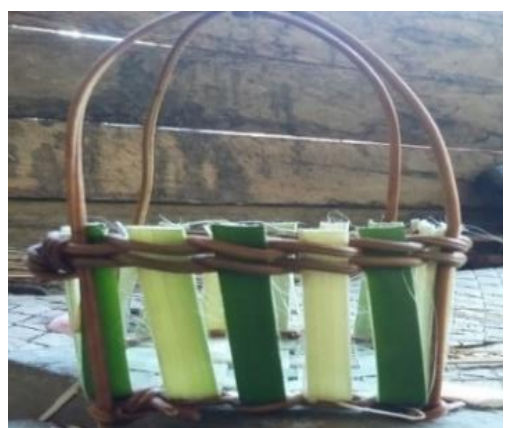

(a)

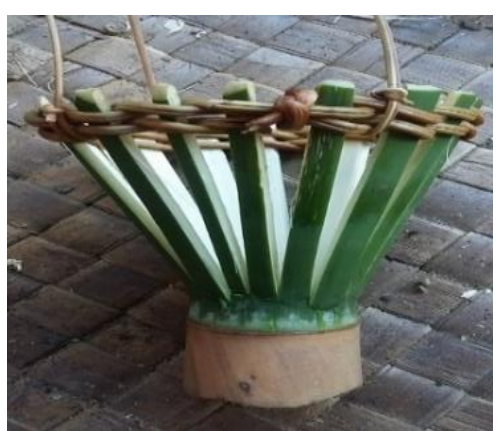

(b)

Gambar 5. Bambu untuk Ritual (a) Kelongkang Sasak (b) Kelongkakng Bukuk (Bamboo for Rituals (a) Kelongkang Sasak (b) Kelongkang Bukuk)

\section{Bambu sebagai Alat Pertanian}

Masyarakat Desa Landau Garong juga memanfaatkan bambu sebagai alat pertanian seperti tempurong karet. Biasanya bambu yang digunakan sebagai alat pertanian adalah bambu ao (Bambusa vulgaris var. vulgaris) dikarenakan jenis bambu ini berdinding tebal dan tahan lama, dapat digunakan 1 atau 2 tahun pemakaian.

\section{Tempurong Karet}

Tempurong karet yaitu berfungsi untuk menampung air getah karet. Tempurong karet berbentuk runcing memanjang. Cara menggunakan tempurong karet yaitu letakkan tempurong di bawah saluran air karet.

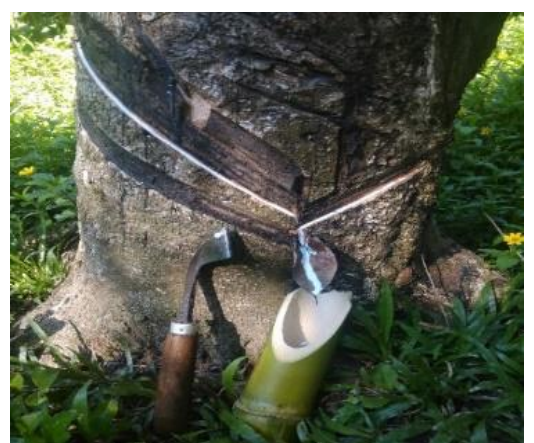

Gambar 6. Bambu untuk Pertanian (Tempurong Karet) (Bamboo for Agriculture (Tempurong Karet))

\section{Bambu sebagai Bahan Alat Permainan Tradisional}

Bambu dimanfaatkan masyarakat Desa landau Garong sebagai bahan permainan tradisional seperti senapang lepok. Bambu yang digunakan untuk membuat senapang lepok adalah bambu porin manis (Gigantochloa levis) dan menggunakan batang yang lebih kecil, dikarenakan mudah dibentuk. Menurut hasil penelitian Rikardo et.al (2015) masyarakat Kecamatan Sobang Pandeglang Banten juga memanfaatkan bambu sebagai bahan seni seperti angklung dan layangan. Bambu yang digunakan untuk membuat angklung dan layangan adalah bambu mayan (Gigantochloa robusta Kurz). 


\section{Senapang Lepok}

Senapang lepok digunakan anakanak sebagai mainan. Senapang lepok terbuat dari bambu porin manis, senapang lepok berbentuk bulat panjang. Cara menggunakan senapang lepok yaitu basahkan peluru terlebih dahulu (buku tulis), masukkan peluru ke dalam lobang senapang lalu pukul-pukul hingga peluru terlihat tipis dan rata. Kemudian masukkan batang bambu lalu dorong.

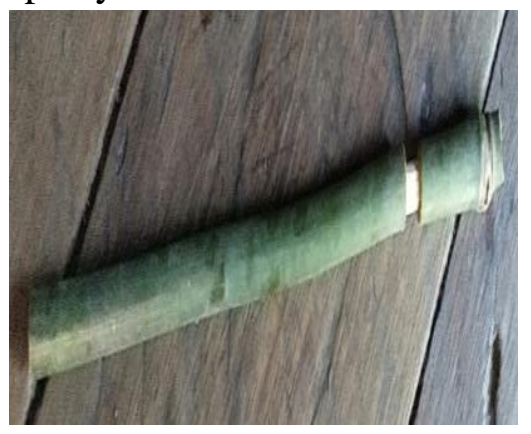

Gambar 7. Bambu untuk Permainan Tradisional (Senapang Lepok) (Bamboo for Traditional Games (Senapang Lepok)

\section{Kesimpulan}

1. Terdapat 6 jenis bambu yang dimanfaatkan oleh masyarakat Desa Landau Garong Kabupaten Melawi. Jenis-jenis bambu tersebut adalah (Gigantochloa hasskarliana), (Bambusa vulgaris var.vulgaris), (Schizostachyum brachycladum), (Schizostachyum flexuosum), (Gigantochloa balui) dan (Gigantochloa levis).

2. Jenis-jenis pemanfaatan bambu oleh masyarakat Desa Landau Garong berupa bahan material bangunan, bahan kerajinan, bahan pangan, bahan ritual, bahan pertanian dan bahan alat permainan tradisional.

\section{Saran}

1. Masyarakat diharapkan melakukan pembudidayaan untuk jenis (Gigantochloa levis) agar keberadaan bambu tersebut tetap lestari, karena jenis bambu tersebut jumlahnya sedikit.
2. Mengingat potensi bambu dan pemanfaatannya yang cukup banyak, perlu dilakukan pelatihan agar keterampilan kesenian masyarakat semakin meningkat dan menjual jenis pemanfaatan tersebut untuk menambah nilai perekonomian.

3. Masyarakat diharapkan dapat menambahkan pewarna alami untuk kerajinan, supaya kerajinan tersebut terlihat menarik.

\section{DAFTAR PUSTAKA}

Arsad E. 2015. Teknologi Pengolahan Dan Manfaat Bambu. Banjarbaru. Jurnal Riset Hasil Hutan 7 (1) :45-52.

Munziri, Linda R, Mukarlina. 2013. Studi Etnobotani Bambu Oleh Masyarakat Dayak Kanayatn Di Desa Saham Kecamatan Sengah Temila Kabupaten Landak. Pontianak. Jurnal Protobiont 2 (3) :112-116.

Murti, K.A.H dan Murwandani, N.G. 2018. Kerajinan Anyam Bambu Di 
Sanggar Hamid Jaya Desa Gintangan Kecamatan Rogojampi Kabupaten Banyuwangi. Jurnal Seni Rupa, 06 (01) :634-644.

Rahmawati, Baharuddin, Putranto B. 2019. Potensi Dan Pemanfaatan Bambu Tali (Gigantochloa apus) Di Desa Leu Kecamatan Bolo Kabupaten Bima. Jurnal Perennial 15 (1) :27-31.

Rikardo R, Susilo H, Suyamto. 2015. Etnobotani Bambu Mayan (Gigantochloa robusta Kurz.) Di Kecamatan Sobang Pandeglang Banten. Jurnal Sci. Phar 01 (01) : 42-49.

Sudjana, D. 2001. Metode dan Teknik Pembelajaran Partisipatif Bandung: Falah Production.

Usman. 2019. Pemanfaatan Bambu Oleh Masyarakat Desa Babane Kecamatan Samalantan
Kabupaten Bengkayang. Jurnal Hutan Lestari 7 (2) : 655-667.

Vorontsova, M.S, L.G. Clark, J.Dransfield, R. Govaerts, W.J. Baker. 2016. World Checklist Of Bamboos And Rattan. INBAR. Technical Reports No. 37.International Network For Bamboos And Rattan \& The Board Of Trustees Of The Royal Botanic Gardens, Kew. 467 hal.

Widjaja, E.A. 2001. Identikit Jenis Jenis Bambu di Jawa (Identity Kits for the bamboo species in Java). Pusat Penelitian dan Pengembangan Biologi - LIPI, Balai Penelitian Botani. Bogor, Indonesia. $101 \mathrm{pp}$.

Widjaja, E.A. 2019. The Spectacular Indonesian Bamboos. Polagrade. Jakarta. 188 hal. 